\title{
Both here and there: Diasporic youth in Denmark as agents of development: Based on two qualitative studies*
}

\author{
Rashmi Singla, Anne Sophie Fabricius \& Anne Holm
}

\begin{abstract}
This article investigates some psychological aspects of South Asian diasporic youth in Denmark with focus on the socioeconomic strategies based on two empirical studies. The first longitudinal study explored young adults' economic strategies in relation to their country of origin. The original investigation was conducted in the mid-1990s. Within a theoretical framework combining positioning theory with life course perspective, in-depth interviews were conducted with young adults of Indian and Pakistani background $(n=5)$. The second study focussed on second generation Pakistani descendants in Denmark and their remittance to Pakistan. The extent and nature of transnational activities among second generation Pakistani has been investigated within a theoretical framework of transnationalism and identity construction. The results indicate three emergent forms of socioeconomic strategies among South Asian youth in Denmark: 1) individual strategies involving professional, business related investment and direct remittances, 2) awareness of parents' strategies, although few or no selfinitiated strategies and 3) collective strategy through an organisation addressing their position as agents of development in the country of origin. There are considerable temporal as well as qualitative differences in these strategies as compared to the parental generation.
\end{abstract}

Keywords: youth; diaspora; transnationalism; interviews

Please cite this article as:

Singla, R., Fabricius, A. \& Holm, A. (2011). Both here and there: Diasporic youth in Denmark as agents of development: Based on two qualitative studies. Qualitative Studies, 2(1): 31-49.

\section{Introduction}

In the expanding literature on diasporic communities in various parts of the world, there is a growing emphasis on the connections between the communities' country of residence ${ }^{1}$ and country of origin, often identified as transnational relations. Most research of diaspora is focused on parental generations and the ways in which they preserve contacts to their social networks and families in their country of origin. In recent years, the migrants' descendants' engagement with their parents' country of origin has also been investigated (Levitt \& Waters 2002, Rai \& Reeves, 2009, Raghuram \& Sahoo, 2008). Although studies such as Rumbaut (2002) suggest that second generations are primarily attached to the country of residence, it is too premature to conclude that transnational practices will disappear among the subsequent generations. The subsequent generations' attachment and their significance for the sending and receiving countries have to be investigated (Levitt 2001). Persistence of ties to the country of origin has been focussed in what is known as the "transnational optic", redressing the lacuna created by the primary focus on the adjustment process in the post migration context (Kivisto \& Faist, 2010).

In the Danish context, we have recently seen a number of studies dealing with the economic dimensions of migration and especially migrants' integration in the host communities, or alternatively, with migration and kinship. These studies have shown vital significance of family in the migration process and that kinship networks act as important channels of 
communication, remittances and recruitment for transnational marriages. Diasporic networks are characterized by the simultaneity of (local) places and (global) spaces (Qureshi 1999; Singla 2004b; Rytter 2006). A combination of economic, cultural and psychosocial dimensions, however, is largely left out from these discussions. This article combines these dimensions with the purpose of examining some aspects of the complex situation of a group that is hardly covered in the existing body of literature - the South Asians in Denmark.

Our article is based on two recent empirical studies, the first about the life trajectories of young south Asian adults (Singla 2008) and the second about Pakistani youth in Denmark as agents of development in the country of origin (Fabricius \& Holm 2007). ${ }^{2}$ These studies add to the discussion of the role of diaspora in the economic and social developments in the country of origin. The aim of the second study is to investigate the nature and extent of transnational activities among the Pakistani descendant in Denmark of significance to development in Pakistan. The question asked is how we can see Pakistani descendants in Denmark engage as development agents in Pakistan. We focus on the Pakistani descendants' remittance pattern and how it is affected by their being brought up in Denmark. The broader strategy of the Pakistani descendants in Denmark in relation to development in Pakistan is of great significance as the transformations in economic strategy from the first generation migrants to their descendants over time can affect the economical support to Pakistan from overseas. However, we are also aware that along with contributing to development, remittances also have negative side effects, as they may add to economic inequality and increase dependency among the receiving families.

\section{Migrants in Denmark}

We attempt to paint the Danish scene with a broad brush in order to comprehend interplay between the macro and the micro aspects. In Denmark, ethnic minorities constitute about $9.8 \%$ of the total population of 5.56 millions in January 2011, Approximately 6,5\% of ethnic minorities are from non-Western countries. There are 6621Indians, out of which 1171 are descendents that have been born in Denmark. There were total 20626 persons with origins in Pakistan and 9251descendants of Pakistani parents in Denmark (Danish Statistics, 2011). Many of the migrants were children when they came to Denmark, which means that the Pakistani community is relatively young. It is noticeable that approximately $1 / 3$ of the persons with origins in India and 2/3 of persons with origin in Pakistan have Danish citizenship.

Significant immigration to Denmark began in the late 1960s with the arrival of labour migrants from Yugoslavia and Turkey, as well as a small number from non-European countries (mainly Pakistan and North Africa). The largest numbers of migrants are concentrated in Copenhagen County and its sub-districts, followed by Aarhus, the second largest city, and Odense, the third largest. As in other European countries, migrants in Denmark settled mainly in decaying inner city areas or in newly constructed high-rise suburbs around the larger cities.

In Denmark, the majority of ethnic minorities are to be found at the lowest end of the labour market in terms of skills and qualifications or in self-employment. In the present situation, inter-ethnic relations are rather strained as intolerance and right-wing extremism have increased. Tougher restrictions have also been introduced on the acquisition of citizenship through naturalisation. Family reunification has been tightened to such an extent that today it is virtually impossible for the members of ethnic minorities from non-Western countries to be united with their spouses in Denmark, unless a range of conditions are fulfilled by the applicants. These factors place Denmark rather low in parameters of the Migrant Integration Policy Index - MIPEX, whereas ethnic minorities have relatively higher placing on the political participation parameter. 
Recent research indicates that in current public, media and political discourse, the terms 'ethnic minorities' and 'immigrants' are unconsciously associated with Muslims. Muslims constitute the majority of all non-Western immigrants and their descendants, as well as the single largest group among all minority faith communities in Denmark. At the same time, it is important to note that there are ethnic minorities belonging to faiths such as Christianity, Hinduism, Sikhism and Buddhism (Singla 2008). Indians and Pakistanis are perceived as relatively successful in their economic and social integration in Denmark, especially as they have higher levels of education and self-employment than other ethnic minority groups, in spite of the generally low position of ethnic minorities in the labour market (Qureshi 1999).

According to a recent report by United Nation's Fund for Agricultural Development (IFAD), 1,500 billion kroner are sent as remittances from Western countries to "developing countries," and out of these, 578 billion are sent to Asia. IFAD considers this transfer of money as the "human face of globalisation," while some scholars in Denmark consider this a barrier for migrants' integration (Andersen \& Kjær 2008). In the Danish context, migrants send up to 10 billion kroner to their country of origin every year. Ballard (2004) notes that these figures cover only half of the total amount of remittances, as there are informal transfers of money going on. In the South Asian case, these depend on a value transfer system known as Hawala.

Due to demographic changes and strict immigration laws, the number of first generation migrants is shrinking and the generation of descendants that may take over the responsibility of sending remittances is increasing. This article aims to cover some micro-level aspects of the descendants' socio-economic strategies partly from the subjective perspective of the young persons, thus addressing interaction between agency and structure.

\section{Theoretical framework}

The theoretical framework of the first study combines social psychological and anthropological perspectives. In this framework, the youth appear as active agents and their relation to the context is seen as dialectical. The present study is a follow-up of an earlier study (Singla 2004b), conducted in a context characterised by radical modernity, which involved resolving the tension between indiviualism and communality (Dencik 2005). Furthermore, a life course perspective (Levy et al. 2005) is combined with positioning theory (Harré \& Moghaddam 2003). The study recognises that intersections of important forms of social stratification such as ethnicity, age, class, gender, and nationality bear significantly upon diaspora histories (Phoenix 2008, Sen, 2006), though ethnicity and age are here in the foreground.

The second study has a combined focus on transnational activities and identity construction. The purpose of combining insights from these approaches has been to try to bridge a gap between Pakistani descendants' construction of identity within transnational social fields and their actions as development agents. We consider that the lives and everyday strategies of many second-generation Pakistani are oriented towards and developed in relation to more than one national context, and that their transnational orientations are not necessarily obstacles to their national feeling of belonging (Yuval-Davis 2006). There is a complex interaction between national and religious belonging characterised by two emergent tendencies. The first tendency points to being a Muslim first, without attaching significance to geographical locations, while the second implies being a Muslim along with a national identity such as Muslim of Pakistani background living in Denmark (Khawaja 2007). It is thought-provoking to contemplate with Brah (2007) that in the late modernity in terms of our identifications (or contra-identifications, 
for that matter) we are all diasporised across multiple social and psychological 'borders' and share a 'homing desire' for security and belonging.

Major discussions to which we contribute, concern transnationalism and diaspora, both of which have diffused widely over the past years. These terms have been embraced not only by mobile people themselves, but also by international organisations and state authorities. A relatively new concept, transnationalism is not limited to migration-related phenomena, but refers to a wider class of actions, processes and institutions that cross the boundaries of states or national communities. In the contemporary literature, the notion of transnationalism has been generally used to refer to migrants' ongoing ties with source countries. Transnational migration can be defined more broadly as a triangular relation between migrants, source and destination countries. Guarnizo (2000) delineates variations in the intensity and frequency of transnational practices by defining as 'core transnationalism' those activities which are integral parts of the individual's life. These activities are patterned and thus somewhat predictable. 'Expanded transnationalism,' in contrast, includes migrants who respond to political crises or national disasters by engaging in occasional transnational practices. The second study is an example of expanded transnationalism, while the first one illustrates core transnationalism. ${ }^{3}$

Like transnational, the term diaspora has achieved significance beyond the realm of migration, and in some discussions it signals a broader postcolonial debate on overcoming Eurocentric approaches, for example in Paul Gilroy's The Black Atlantic (Kalra, Kaur \& Hutnik 2005). Dufoix (2008) proposes a broader conceptualisation of diaspora as a dispersal process which implies distance. Thus maintaining or creating connections becomes a major goal in reducing or at least dealing with that distance. On the other hand, Anthias (2006) proposes that diaspora could be used to counter the essentialism found in many traditional approaches to ethnicity, as diasporic bonds may weaken transethnic bonds with other groups which are involved more local or national contestations and struggles. In short, while in some contexts diaspora relates to parochial concerns of nation-state formation or secession, in others diaspora figures as a symbol related to new forms of cosmopolitan stance, which represents a capacity to live in multiplex environments and have multiple identities, implying belongings across state borders. In our article diaspora connotes a broad range of connections across borders.

In the past decades, the attitudes and actions of sending countries have transformed, which makes such connections possible. Sending countries have started to actively support diasporas' engagement in development cooperation, tapping into the allegedly rich resources of financial remittances, human capital and 'social remittances' transferred, among other channels, through diaspora groups, such as religious communities and hometown associations. In other words, a new development agent is emerging. For example, some states with significant rates of emigration, such as the Philippines, Vietnam and India, have stopped calling their citizens abroad "traitors" and celebrate them as "our heroes" with the motto of "engaging the diaspora: the way forward" (Bamzai 2004; PBD 2008). A series of programmes like Know India and Scholarship for Diaspora Children, along with a new focus on the preservation of language and culture in diaspora and the importance of migrants as facilitators and bridge builders further illustrate these tendencies. Naidoo (2005) and Guzder \& Krishna, 2005 note that sending countries such as India are attempting to woo their diasporic populations to share their knowledge and experiential and economic capital by emphasising the economic advantages of investing in the country of origin. These practices lead to sort of dual memberships in the country of origin as well the country of residence. Levitt (2001) suggests that the proliferation of these dual memberships contradicts conventional notions of immigrant incorporation, 
migrants' impact on sending countries, and the relationship between migration and development in both contexts.

In this article, we stress the subjective features of diaspora populations, the agency (the meanings held and practices conducted by social actors) and the multiple meanings of diaspora, especially the perception of diaspora as a social form (Vertovec 2000). We also conceptualise diaspora as a psychological consciousness and mode of cultural production/consumption. Diaspora as a social form is about relations, networks, and economic strategies across borders while consciousness is awareness about multi-locality, both here and there, connection with others who share similar roots and routes.

Kalra et al. (2005) criticise the idea of migration as a one-way process in which people migrate from one place and settle in another and argue that an understanding of complex transnational identities needs new conceptual maps. They conceptualise diaspora both as a positive embracing of transnational affiliation as well as a defensive posture in the face of a hostile host saying "you do not belong." The theoretical point of departure is that transnational involvement and incorporation in the country of residence coexist and in some cases mutually reinforce each other (Levitt 2001). These border-crossing processes imply the formation of transnational communities that challenge the assumption of the nation state as the natural social and political form of the modern world (see Wimmer \& Glick Schiller 2002 on methodological nationalism in social science).

\section{Research methodology}

Both studies were based on in-depth interviews with people of South Asian (Indian and Pakistani) background, approximately 30 years of age. In the first study, Singla conducted interviews with 9 of the 14 young adults who had been interviewed approximately 10 years ago in the first wave of the study in the greater Copenhagen area (Singla 2004a, 2004b). Among the young adults, only one - Mita - was Hindu/Sikh, while the others were Muslims.

Re-establishing contact after a decade was rather demanding and two of the informants could not be traced due to lack of cooperation by gatekeepers- in-charge of the youth residential institution, while two were not healthy enough to be interviewed. Attention was paid to the ethical issues involved and creating a balance between the insider and outsider perspective in the dynamics of linguistic and ethnic matching between the informants and the researcher (Kvale \& Brinkmann 2009, Singla 2004b). A perspectival subjectivity - adopting different perspectives and posing different questions on the same themes - contributed to formation of explicit questions based both on the first wave findings and a theoretically informed questioning including the new literature (between the first and the second wave).

The informants were given a choice of languages for the interview as there was ethnic and linguistic matching between the researcher and the informants. Out of the 5 informants with South Asian background, the choice was English for one, mother tongue Urdu / Punjabi for another and a mixture of Danish and Urdu for the rest. The interviews were conducted in the researcher's NGO, to which all the informants had agreed. They were tape recorded and transcribed in English.

In order to investigate young adults as agents of development, Fabricius \& Holm (2007) conducted a case study based on second generation Pakistani volunteers in a Danish NGO called Danish Muslim Aid (DMA). The study looked at Pakistanis' engagement and motivation in relief projects as well as long-term projects that DMA has established in the Nora Sheri 
District in Northern Pakistan, hit by an enormous earthquake in October 2005. The case demonstrates the active role of migrants not only long-term but also in emergency aid and their assistance in reconstructing the province. DMA is a religious organisation established in 2005. Its members have multiethnic social networks based on religion, though according to the organisation's website, it provides aid across ethnic, religious and political borders. Besides emergency relief, other activities include sponsorship of orphaned children in many developing countries, dispatching new and used hospital and school equipment where needed, school and water projects as well as micro-financing projects.

Fabricius \& Holm (2007) have picked out this organisation because they see it as a representative of a new way of sending collective remittances. They conducted qualitative interviews in Pakistan and in Denmark. In Pakistan they interviewed 3 officers responsible for projects and 7 volunteers, as well as 3 of their beneficiaries. To compare DMA's development work to other projects in the area we interviewed the Danish ambassador in Islamabad, 3 Pakistani journalists who have reported from the earthquake area and the leader of Pakistani Center for Philanthropy. In Denmark, 8 interviews were conducted with second-generation Pakistanis. All interviewees had Islamic backgrounds. The informants were interviewed in their homes, in a suburb of Copenhagen, in Danish language.

The main analysis in this article builds on meaning condensation of narratives, followed by their categorisation in post hoc categories, noting patterns. To sharpen understanding, the analytic strategy of making contrasts/comparisons was used (Kvale \& Brinkmann, 2009). In interpreting the narratives, the focus was on the spirit rather than on the letter of the interview texts. A theoretically informed reading of interviews, especially a combination of realist and critical reading led to a search for participants' points of view as well as calling attention to the broader issues seeking a deeper truth underlying the hegemonic discourse of the interview texts (Ibid, p. 236).

A conceptual framework of push and pull factors is developed to analyse factors connecting second generation migrants to the country of origin as well as the country of residence. In the first study, the longitudinal research design made analyses of the informants' earlier intentions and their realisation possible (Singla, 2005, Singla 2008). We focus here on the economic strategies used by the young adults in relation to their country of origin. Economic strategies are seen as ways of maintaining contact with the country of origin involving monetary transaction in variety of forms such as direct economic assistance, indirect assistance in procurement of goods, investment in real estate, and payment to employees.

\section{Results}

Social relations and strategies across geographical borders:

The study sheds light on the socioeconomic aspects of transnational relations, consisting of migrants' relationship to the ancestral country and their relations with the diasporic community in the other parts of the world. The myth of return as an archetype of diaspora is indirectly included. We have placed the young adults in the following post-hoc categories:

1. Comprehensive strategies

2. Limited contact and strategies 


\section{Comprehensive economic strategies}

This analysis indicates paradoxes in the psychosocial understandings of the young adults. Mita, a young Indian woman, illustrates this well: She has comprehensive contacts to her ancestral country because of her marriage to an Indian spouse and their business relations to a major city in India. ${ }^{4}$ She is the only respondent who has been to India eight times in the past decade and also has business and familial relations in the UK. She mentions economic strategies related to the company employees in India and emphasises that there are no economic obligations to the in-laws family as they are economically well off and encourage the couple's endeavours. Mita's economic strategies are an example of the positive effects of transnational investment through creation of jobs - a 'productive' investment in contrast to spending on consumer goods, although her strategy doesn't entail sending of cash remittances (Vertovec 2004).

Aman [husband] is only paying his staff in India and he would try to put some money to develop his company in India... The family support is none, as my in-laws don't want to take any. They say build your own.

Mita proclaims her connection and gratitude for Denmark as her country of birth and upbringing, providing "settlement for life" along with positive feelings for her country of origin that she didn't have earlier due to limited contact.

Denmark is my country because I am born here... But what I gained in Denmark is simply my settlement for life. Got my education here, came back and the first future and everything I need for progress in life, I got it here... I do belong to Denmark. But I love India as well.

Mita is reflexive about her positive feelings and connection to both countries and seems to be content with the present solution of their business relations between India and Denmark. At the same time, she expresses critical views about the stigmatisation and restrictions of ethnic minorities in Denmark.

So we both are mixing it together and it is going very well for our company. If I can succeed this way, I am not going to feel that I miss anything... have both of the things I want. ... Tomorrow my dream is to work in India. To give myself such a status in the company that I can go and live there forever....The Danish culture is very restricted ... are not very open to foreign cultures.

Mita is also affiliated through her parents to a Hindu religious sect originating from India, and contributes once in a while to the sect, which has branches not only in Denmark but also in Germany and the UK.

Mita's economic strategies have to be seen in the context of changes in her life course as well as the structural changes in India and Denmark. She had no plans of becoming established in India or Denmark at the time of the original study (Singla 2004b) and wanted to get married and settle in the UK. Transitions in her life-situation - high educational achievement, self-chosen marriage with a South Indian of the same profession as herself, and her father's illness in Denmark have been the pull factors for her economic strategies at personal level. At the same time, economic growth in India, especially in the bio-technical sector with export potential, is the main reason at the structural level. Her economic strategies are different from her parents', who only sent economic remittances during the first phase of their stay in Denmark as long as Mita's grandmother was alive. Now they have very limited economic activity in relation to the religious sect in India they have been affiliated to. 
Nadia is the only other young adult who has comprehensive economic strategies in relation to her country of origin and paradoxically the only one who has not visited Afghanistan and Pakistan at all since she arrived in Denmark about 15 years ago. Political uncertainty in her country of origin pushes her away. Some of her maternal family lives in Australia and Pakistan, while her paternal family, with whom there is telephone and Internet contact, has moved to Germany and the U.S.A. Nadia has a well-defined and motivated economic strategy in relation to the family living in Afghanistan, as she sends money to them every month, while another family member from Germany also supports her uncle's family in the country of origin. These economic strategies illustrate the significance of remittances for the extended family in a catastrophic situation in a country at war. She can be positioned as a compassionate family member, having multiple diasporic relations in many contexts. Nadia's parents also support her mother's family of origin economically, as her father's family is well to do. Her remittances can be perceived as essential for the extended family's survival, but they can hardly be argued to lead to the negative impact of economic dependence (Vertovec 2004), given the situation of Afghanistan, and the practice can be called core transnationalism according to Guanizo's conceptualisation.

We have my mother's family in Afghanistan. Our contact is that we send money to them every month. I send money to my grandmother and to my mother's sister. I have chosen to send money to them.... My mother's sister in Germany sends money to my uncle's family ... my father's family, many of them are millionaires, and they have businesses.

In contrast to Mita, Nadia has no economic affiliations to any religious organisation. On the other hand she contributes to "cosmopolitan" organisations like Red Cross, Refugee Help, Amnesty International and Green Peace. She justifies her decision as: I appreciate them.

On the whole, Mita and Nadia's direct economic strategies differ from the other young adults, who have very limited or no direct economic connections to their country of origin, as can be seen in the next section. Furthermore, there is no proportionality between direct social contact, such as number of visits, and the economic strategies, as Mita has visited India eight times and Nadia has not been on a visit even once, yet both make regular economic contributions.

The parental strategies are also highly differentiated. Mita's parents do not send remittances at the moment, though her grandmother used to receive remittances for a number of years. On the other hand, Atim's parents spend 3-4 months a year in their country of origin and have substantial economic strategies as well as high level of participation in their transnational network. The concept of transnationalism from below may describe these strategies, though with a large variation.

\section{Limited strategies}

In contrast to Mita's and Nadia's comprehensive economic connections to their ancestral country, other young adults, Abdul, Salman and Atim, have almost no economic strategies in relation to Pakistan. However, they explicitly mention their parents' close relationship with the country of origin.

My parents have kept contact with the country of origin... They have not forgotten where they came from. 
In the original study Abdul was very connected to Pakistan, where he had studied in a boarding school. He was also psychologically attached to his father's older brother. He visited Pakistan only twice in the past decade and he singled out economy and property-related conflicts between his father and uncle as reasons for their estrangement.

Like Abdul, Salmon has rather limited connections with his ancestral country due to conflictual relations in the extended family and his wife's Afghani background. However, he attended his younger brother's wedding in Pakistan. His narrative of less frequent contacts after the grandparents' demise can be understood through the life course perspective, while marriage outside the family, in contradiction to dominant norms of Muslim extended family endogamy, is another reason for the diminished contact. Likewise, family conflicts pertaining to property in Salman's narrative can be seen as a pushing away -factor from the country of origin. These conflictual relationships also illustrate that South Asian families can be supportive when it goes well, but when things go badly, the consequences can be disastrous (Ballard 2005).

Rest of our family live in Pakistan. My parents keep in contact. We are an extended family with lots of conflicts, partly because my parents chose to get their children's spouses from outside the family and partly because of some property matters... these are the reasons for the distance within the family. We visit them though. We had a closer relationship with the family when my grandparents were alive. After their death it is not the same.

However, as a company owner, Abdul travels comprehensively and has an international business network.

I have business contacts in countries like Italy, America, and Korea and Germany. I travel twice a year to these countries.

These narratives illustrate lucidly that economic strategies are related to an array of complex factors not only at the personal level, such as the spouse's national background, but also salient interpersonal factors such as relationships within the extended family. Additionally, interpersonal dynamics are influenced by life course transitions such as demise of the older generation in the country of origin. Congruently, life course transitions can be seen as making intergenerational changes in economic strategies understandable. However, the results from the second study indicate that there can be other grounds for remittances than solidarity within the extended family.

\section{Migrants' descendants as agents of development}

The informants contributed to economic development in Pakistan in the context of a natural disaster, which can be seen as expanded transnationalism (Guarnizo 1997). But the findings suggest that the informants have a high level of identification with different cultures in both Pakistan and Denmark in accordance with the second tendency delineated by Khawaja (2007). It seems that their capabilities and desires to participate in transnational activities related to development are very individually influenced by the way they are brought up and the connection to the family's social network in Pakistan. These informants contribute less through individual remittance and more through collective remittances.

The traditional tax paid by the informants, Zakat, ${ }^{5}$ is used for other purposes than the family. The informants have an opportunity to pay Zakat via a giro-card through DMA and they support DMA projects both in Pakistan but also in other counties where DMA works, for 
instance Uganda. The aid is not religiously conditioned as such, but the informants describe that their contributions are a religious obligation.

The group of informants in Fabricius and Holm's study (2007) is a religious group and we are aware that that may have influenced their way of presenting their motives. We try to take into consideration the many aspects and variations in the lives of these second generation Pakistani. It is difficult to distinguish between identity-driven and structurally driven causes for their activity, but we argue that their religious identity combined with the national one is one of their main reasons to engage in development in Pakistan.

The Pakistani descendants broach that the difference between them and their parents as agents of development is that the they call for transparency. From their own point of view there is more interest in and concern about the development projects and processes for which remittance are used. They explained that their parental generation largely support their family or a mosque, although driven by the obligation to pay Zakat. They derive satisfaction from their payment. In other words, the parents are satisfied with the action rather than the results, whereas the informants themselves emphasise their interest in the actual results.

It is not tradition to get feedback from the mosque in the same way as we do it [in DMAid]. I don't know if it is a typically Muslim thing, but it is something like that what counts is that you support a good cause (...), whether or not the money actually ends in the hands of those in need. Maybe there are some that cheat or something like that, that is not your problem. You have gained what you wanted out of it. So therefore there is no tradition for feedback. Some make demands on what it is used for but the majority of my father's generation do not. (Nadeem)

The informants argue that some of their generation and especially their children in the future will channel their support less individually and those who will support do so by sending collective remittances through organisations like DMA.

I have the feeling that my generation and the generation that follow me. (...) Many of them will support through organisations. (Nadeem)

Collective remittances can help to minimise the economic gap between families who have migrant members in foreign countries and others in a local society in Pakistan because they support those who need the help most. On the other hand, one can argue that members of the parental generation know more about the needs of the local society than the descendants who are brought up in Denmark. Thus the parental generation, paying attention to how their remittances were used, might have helped the needy in the local community.

\section{From national level to cosmopolitan level}

We found that volunteers in DMA glorify their own way of contributing to development worldwide and do not in the same way value their parental generation's way of supporting Pakistan. Some young people mentioned that their parental generation has also sent remittances to development projects similar to theirs; building schools or paying school fees for children. The difference is that collective remittances are not sent with the same local attachment by the younger generation. The informants explained that most of their families were in Europe and that the connection to Pakistan was somehow disintegrating, except for those who had married a Pakistani from Pakistan. 
We are influenced by the Danish culture, Danish association-culture, a Danish way of thinking, a Danish way of arguing. In connection to organisations we are inspired and influenced by the Danish society also in when it comes to culture and religion. (Hussain)

Five of the informants support DMA projects in Pakistan and the majority of the informants still feel a connection to their parents' local society in Pakistan. Besides the collective remittances, they send individual remittances through the family network.

I think that most of them [the second generation] support on two levels - the one we are brought up with and have seen our parents do and then we also support on another level by engaging ourselves in organisations. (Humma)

Three informants underlined that they support the organisation's projects in Africa but the rest support projects in Pakistan. Some of them describe it as a tendency that will grow in their children's generation. This religious group (and probably their children) will keep on sending money to a developing country because they fulfil a religious obligation to do so, but the focus might not continue to be on Pakistan. Additionally, the results show that the youth are supporting development at a broader level compared to the relatively narrow extended family economic support given by their parents. These practices can be understood as cosmopolitism a broader, more international position with a varied supportive network, transcending the national borders (Frello 2006).

\section{Discussion}

The analyses based on the young adults' narratives add nuances to the understanding of the socio-economic dynamics of diasporic groups by combining a social psychological framework with broader social-economic conceptualisations.

The young South Asians' narratives illustrate the vast variation in the economic strategies within the diaspora. Regular remittances either as payment for the employees of one's own firm, economic support to the extended family or to development projects in the ancestral country are at one end of the continuum, while the other end is illustrated by young people who do not send any remittances at all to the country of origin. Ballard (2008) also concludes that in an unstable world, corporate, collective families deploying strategies involving fulfilment of obligations do enjoy some degree of coherence and stability. However, there are necessary costs: the attenuation of personal freedoms of choice.

On the other hand, some young people are sending remittances at a broader cosmopolitan level through organisations to different parts of the world, transcending the narrow national borders. Cohesion of the diaspora group hardly interferes with their integration in the country of residence (Levitt 2006). Congruently Vertovec (2004) also regards the polarisation between transationalism and adaptation in the country of residence as a false dichotomy and notes that these developments do not always entail a clash of social worlds. He delineates the impacts of transnational practices on families' perceptual orientation, and emphasizes the sense of dual orientation well as changes in value systems across whole regions. Similarly, Guarnizo (1997) sees the transnational habitus as a set of dualistic dispositions - a set of dual references through which comparisons of migrants' situation in the 'home' to their situation in the 'host' society takes place, pertaining primarily to first generation migrants. 
The current analyses show that some youth like Mita are active diaspora members as well as constructive members of Danish society, while some, like Salman, show a relatively low level of transnational involvement. Furthermore, attention is directed to the continued social relations and economic strategies of the young adults in the country of origin. Intersectionality of informants' own ethnic identity with the family history, educational and economic level and the ethnic/regional identity of the partner influence the extent and quality of these contacts (Phoenix 2006).

At the same time, life course transitions such as marriage with a partner from the country of origin and tragic demise of a family member also plays a part. Interpersonal reasons, like a business firm/extended family situation, religious/spiritual reasons and structural factors such as business potential, economic hardships and catastrophe in the country of origin seem to be more relevant for understanding these different economic strategies as well as the economic strategies of the parental generation. The parental strategies are also highly differentiated, as some send no economic remittances while others have substantial economic commitments. And some of the parental generation also send remittances to development projects.

In spite of these differences, all the young adults point to their belonging to the country of origin in different ways. As discussed by Fortier, remittances contribute both to the feeling of being included and in possession, which is an important aspect of belonging (in Buciek \& Juul 2008). Moreover, they emphasise the connection between places involving multiple allegiances and belongings as kind of intermediate space between nations and cultures (Buciek \& Juul 2008).

Based on our analyses and discussion, we can point to three emergent socioeconomic strategies among the youth. The first are individual socioeconomic strategies which could be related to business or support for the extended family, while the second one is not having a personal economic strategy, but mentioning a parental strategy. The third one is the collective strategies through organisations, where aid may be directed to the country of origin and/or some other country. The assumption by Guarnizo (2003) that remittances have become the most visible evidence and measuring stick for the ties connecting migrants to the country of origin is challenged by these findings. At the same time, Guarnizo's statement that transnational practices cannot be neatly compartmentalized and nor can their consequences, makes us aware of the arbitrariness and complexities of these strategies.

These results are in congruence with Hole's anthropological study of Indian Gujaraties in Sweden (2005), which indicated substantial intergenerational differences in economic strategies in relation to India. The young generation sent almost no remittances to the extended family in contrast to the parental generation. Among the reasons delineated by Hole are the fact that the young generation is born and brought up in Sweden and have very limited contact with the extended family, and the relative positive changes in the economic status of the extended family in India. Similar results are found among the South Asian diaspora in Norway by Carling (2004). The concept of filial piety implying obligation to help the older generation, especially in time of need (Bachchu 1999; Lau 1986) still has significance but does not lead to transnational economic strategies as both generations now live in the country of residence, unlike the situation for the parental generation.

The increasing significance of the country of residence as the location of displaying economic status at the personal as well as the community level can be another factor related to the 
changes in the economic linkages across borders. Some youth position themselves as belonging to Denmark and they contribute less to individual remittances. However, they still send some collective remittances to the country of origin. This corresponds partly to the conclusion by Vertovec (2004) that the post-migration second and subsequent generations will probably not have the everyday orientation and practices of their forefathers, but these orientations and practices continue to have enduring impression on their identities and activities.

Brown and Talbot (2006) illustrate these changes through the South Asian Diaspora's development of sacred spaces, like ostentatious temples in localities such as Neasden in NorthWest London and South Hall in West London. These sacred organisations also maintain ties to the country of origin through collective economic linkages and visits of Gurus and sages, but also by contributing to the creation and sustaining of psychosocial relations and identities. In another context, among Indians in Trinidad \& Tobago, diasporic consciousness is perceived as an expression of Indo-Trinidadians' agency and is fundamentally political. Seeking to alleviate, or counteract the vulnerability that betrayal and ignorance are perceived to foster, IndoTrinidadians strive for potent visibility in the nationalist ideology through narrative memorializations of injustice and practiced attainments of religious knowledge (Khan 2007). These practices are indicative of the diaspora members' awareness of processes of exclusion in the country of residence. The economic strategies of second generation Pakistani are positive ways of facing the "closure" tendencies in Scandinavian societies, which are relatively milder than the ones delineated below.

What unsettles cultures is 'matter out of place' - the breaking of our unwritten rules and codes. Dirt in the garden is fine, but dirt in one's bedroom is 'matter out of place'- a sign of pollution, of symbolic boundaries being transgressed, of taboos broken. What we do with matters out of place is to sweep it up, throw it out, restore the place to order, bring back the normal state of affairs. The retreat of many cultures towards 'closure' against foreigners, aliens and 'others 'is a part of the same process of purification (Hall 2000, p. 330).

In spite of some experiences of "closure," it is noticeable that none of the young adults had any concrete plans of returning to the country of origin. These findings are congruent with a psychological study of Indians in Paris, in which Parisians were perceived as closed people. Some believed that there was subtle discrimination against outsiders and that people with roots outside France could not reach the top positions in jobs. Despite the fact that the immigrants felt emotionally for India, though there was marked variation as regards to the emotional affinity experienced and expressed towards the country of origin, few had plans to return (Verma 2000).

There are, at the same time, economic strategies among the young members of the diaspora, which indicate a cosmopolitan stance, representing a capacity to live in multiplex environments and have multiple identities. One or another of these multiple identities can come to the fore in any particular setting (Van deer Veer 1999, Bamzai 2004, Singla 2004a).

Socio-economic strategies among the diaspora are marked by the three different trends analysed above, confirming connections to the country of origin as well as a trend towards cosmopolitanism, which co-exist in a complex manner in the lives of some youth. These transnational ties are not contradictory to inclusion into a host country; instead, these two processes seem to occur simultaneously. 


\section{Conclusion}

In the first study (Singla 2007), the major findings about the socialpsychological aspects with focus on the economic strategies of the young South Asians reveal some paradoxical tendencies, a large variation in the direct economic strategies coexisting with the common feature of a diasporic identity with elements from the country of residence as well as the ancestral country. At the same time, the myth of return to the country of origin is hardly realised for the youth, which indicates that the South Asian youth are both here and there, though mostly here. The second study (Fabricius \& Holm 2007) reveals a tendency among a group of young Pakistanis to send remittances from a broader perspective than the narrow local perspective of the parental generation.

We can thus identify three emergent forms of socioeconomic strategies among the South Asian diaspora youth: individual strategies involving professional business-related investment and direct remittances; second, almost no personal strategy but awareness of parental strategy and third the collective strategy through organisation. In the third strategy the religious belongings seem to cement forms of contact and affiliation that are simultaneous global and local. Each strategy has of course different objectives, motivations and ways to conduct influenced by the multifactorial interplay in Denmark as well as the South Asian context, yet the commonality pertains to interconnections between the geographical and/or generational aspects. Some of the questions concerning the subsequent generations raised in the other studies of diaspora and transnationalism have been answered positively - there are patterns of continued socioeconomic strategies among the young generation indicating psychological connections across borders, though in different proportions and forms from those of the parental generation. This challenges predictions of the disappearance of transnational practices (Levitt 2001, Rambout 2002). Finally, our study confirms that the transnational practices of the second generation can often emerge in unexpected forms and in unexpected places.

\section{Perspectives}

We have discussed the complex interplay between micro and macro levels through the transformations in intergenerational economic dynamics in interaction with socio-economic conditions in the country of residence as well as in the country of origin.

Yet there are some unanswered questions, which need to be investigated further. We could shed light on the business-related economic strategies among young diaspora members especially in the context of increasing technological development in South Asia. Furthermore, there could be a development of agencies where transparency could be assured and through which the diaspora could send collective remittances for the broader development of the country of origin instead of the more individual remittances.

Migration from South Asia continues and therefore it is important to investigate what will happen when the young diaspora take over the responsibility of sending remittances, for instance from Scandinavia. How will transnational family relationships be affected by transformations in remittance patterns? How will the intergenerational dynamics be affected by these changes in the country of origin and the country of residence? In agreement with Anthias (2006), we must be careful that the focus on belongings in terms of diasporic attachments does not foreclose a concern with differences of gender, class and generation within diasporic groups. Some groups of young people will probably continue to send some money to some development projects but not necessarily to their country of origin. What will happen to development in the areas which are used to receiving remittances from the parents' generation? 
How will the country of residence respond to these economic strategies; will it perceive them as the human face of globalisation or as proof of a continued connection to the country of origin, implying relatively limited belonging to the country of residence? Will more young people contribute to the cosmopolitan projects? There is a need for further research on these issues across the disciplines of social psychology, economy, diaspora studies and international development.

\section{Literature}

Al-Ali, N., Black, R. and Koser, K. (2001). The limits to "transnationalism": Bosnian and

Eritrean Refugees in Europe as emerging transnational communities, Ethnic and Racial

Studies, 24(4) 578-600.

Andersen, Peter Krogh \& Kjær, Jakob Sorgenfri (2008). Indvandrere sender 10 mia. hjem (Immigrants send 10 billions home) i Dagbladet Politiken 6. januar.

Anthias, Flora (2006). Belongings in a Globalisering and Unequal World: Rethinking Translocations in Yuvaal-Davis, Kannbiran \& Vieten (Eds) The Situated Politics of Belonging New Delhi, Sage p. 17-32.

Ballard, Roger (2005). Forced Marriage, who is conspiring against whom? A paper presented in the University of Roehampton

http://www.arts.manchester.ac.uk/casas/papers/index.html

Ballard, Rogers (2004). Inside and Outside: Contrasting Perspectives on the Dynamics of Kinship and Marriage in Contemporary South Asian Transnational Networks http://www.arts.manchester.ac.uk/casas/papers/index.html

Bhachu, Parminder (1999). Multiple migrants and Multiple Diasporas: Cultural Reproduction and Transformations among British Punjabi Women in 1990s Britain in Singh \& Thandi (ed.) Punjabi Identity in a Global Context New Delhi: Oxford University Press.

Bamzai, Kavita (2004). AB but no Longer CD: Overseas born Indians. India Today. January 19.

Brah, Avtar (2007). Non-binarized Identities of Similarity and Differences in Wetherell, Lafleche \& Berkeley (eds.) Identity, Ethnic Diversity and Community Cohesion, Sage, Los Angeles, p. 136-145.

Brown, Judith and Talbot, Ian (2006). Making Home in the Diaspora: Opportunities and dilemmas in the British South Asian Experience. Contemporary South Asia, vol. 15 (June) pp. 125131.

Buciek, Keld and Kristine Juul (2008). "We are here, yet we are not here" - The heritage of excluded groups, in: Graham, Brian and Peter Howard: Ashgate Research Companion to Heritage and Identity, Ashgate, Aldershot, Burlington VT.

Danish Statistics (2011): http://www.statistikbanken.dk

DM- aid http://dmaid.org/site (2008) 
Dencik, Lars (2005) Mennesket i postmoderniseringen- om barndom, familie \& identiteter i opbrud. Valløse: Bilesø \& Baltzer,

Dufoix, Stephane (2008) Diasporas, London:University of California Press,

Fabricius, Anne Sophie \& Holm, Anne (2008) Transnationalisme på sigt. En Undersøgelse af transnationalisme blandt efterkommere af Pakistanske indvanderere i Danmark. Masters Dissertation, Roskilde University

Frello, Birgitta (2006). Cultural Hybridity: Contamination or Creative Transgression? (s. 1-12). (Amid Working Papers; 54). Aalborg: Academy for Migration Studies in Denmark.

Guarnizo, Luis (1997). The emergence of a transnational social formation and the mirage of return among Dominician transmigrants', Identities, 4, 281-322.

Guarnizo, Luis (2003). The economics of transnational living in International Migration Review.

Guzder, Jaswant \& Krishna, Meenakshi (2005). Mind the gap: Diaspora Issues of Indian Origin Women in Psychotherapy in Psychology and Developing Society vol. 17, nr. 2 (121-138).

Hall, Stuart (2001). The Spectacle of the 'other'. In Wetherell, Taylor \& Yates (eds.) Discourse Theory and Practice Sa ge, London, p. 324-344.

Hole, Elizabeth Åsa (2005). Neither Here - Nor There - An Anthropological Study of Gujarati Hindu Women in The Diaspora Uppsala: Department of Cultural Anthropology and Ethnology

Kalra, Virinder S., Kaur, Raminder and Hutnyk, John (2005). Diaspora \& Hybridity, Sage Publications, New Delhi.

Khan, Aisha, (2007)., Rites and Rights of Passage Seeking a Diasporic Consciousness in Cultural Dynamics, Vol. 19, No. 2-3, 141-164.

Khawaja, Iram (2007). "Muslim allerførst" - om religiøsitet og diasporiske selvkonstruktioner (First of all Muslim- about religiousness and diasporic identities) i Tidsskrift for IslamforskningHverdags islam, nr.2 publiceret 18-6.

Kivisto, Peter \& Faist, Thomas (2010). Beyond A Border: The Causes and Consequences of Contemporary Immigration Sag, New Delhi.

Kvale, Steinar \& Brinkmann (2009). InterView: Learning the Craft of Qualitative Research Interviewing. Sage, New Delhi.

Lau, Annie (1986). Family Therapy Across Cultures in Cox (Ed,) Transcultural Psychiatry, Kent, Croom Helm pp. 234-252.

Levitt, Peggy (2001). Transnational migration: taking stock and future directions.. Global Networks, Jul 2001, Vol. 1 Issue 3, p. 195. 
Levitt, Peggy. (2006). Understanding the Second Generation through a Transnational Optic presented October 2006 in Barcelona at the conference: "Usando Una Perspectiva Transnacional para Entender La Segunda GeneracÓon" Academic Conference Organized by the Jaume Bofill Foundation". (Available at:

http://www.peggylevitt.org/pdfs/Levitt-transoptic.pdf)

Levitt, Peggy and Waters, Mary C. (2002). The Changing Face of Home: The Transnational Lives of Second Generation. Russell Sage Foundation, New York.

Naidoo, Josephine (2005). Editorial: The Asian Indian Diaspora Psychology and Developing Society vol. 17 , nr. 2 (v-vii).

PBD (2008) Pravasi Bhartiya Diwas -website http://www.pbdindia.org retrieved 5.3.2011 ..

Phoenix, A (2008) In Kofoed \&Staunaes (eds) 'Claiming livable lives: Adult subjectification and narratives of "non-normative" childhood experiences', Magtballader (Adjusting Reality). Copenhagen:Danmarks Paedagogiske Universitetsforlag pp. 178-193.

Qureshi, Bashy (1999). Fra Punjab til Vesterbro: det pakistanske samfund i Danmark Etnisk Debatforum, København.

Rai, Rajesh \& Reeves, Peter (eds.) (2009). The South Asia Diaspora: Transnational networks \& changing identities Routledge, London

Raghuram, Parvati \& Sahoo, Ajay (2008). Thinking 'Indian Diaspora' of Our Times in Raguram et al (ed.) Tracing An Indian Diaspora Sage, New Delhi, pp. 1-28.

Rumbaut, Rubén G. (2002). Severed or Sustained Attachments? Language, Identity, and Imagined Communities in the Post-Immigrant Generation in Levitt, Peggy og Waters, Mary C. The Changing Face of Home. The Transnational Lives of the Second Generation, Russell Sage Foundation, New York.

Rytter, Mikkel (2006). Ægteskabelig integration. Pakistanske og danske arrangerede ægteskaber. I Marianne Holm Pedersen og Mikkel Rytter (red): Den stille integration. C. A. Reitzels Forlag, København.

Sen, Amartya (2006). Identity and Violence: The Illusion of Destiny London: W.W. Norton.

Singla, Rashmi (2004a). Youth Relationship and Ethnicity: A Social Psychological Pe.rspective, Young, Vol. 12, no.1, pp.50-70.

Singla, Rashmi (2004b). Youth Relationships, Ethnicity \& Psychosocial Intervention. New Delhi: Books Plus.

Singla, Rashmi (2005). South Asian Youth in Scandinavia: Inter-ethnic and Intergenerational Relationships. Psychology and Developing Society vol. 17, nr. 2, pp. 215- 235.

Singla, Rashmi (2008). Life trajectories, Family Relationships and Diasporic Identities: A follow up Study of Young Adults. Copenhagen Studies in Bilingualism; Copenhagen 
Van deer Veer, Peter (1999). Cosmopolitanism, Secularism and Transnational Religion presentation in the ESRC Transnational Communities Programme seminar, Oxford University, 6 May.

Verma, Jyoti (2000). Report Acculturation experiences of Indian immigrants in Paris, Maison des Sciences de L'Homme, Paris.

Vertovec, Steven (2000). The Hindu Diaspora: Comparative Patterns Routeledge: London.

Vertovec, Steven (2004). Trends and Impacts of Migrant Transnationalism, Centre on Migration, Policy and Society, Working papern.3, University of Oxford, pp.1-78.

Vertovec, Steven (2007). Introduction: New Directions in the anthropology of migration and multiculturalism. Ethnic and Racial Studies vol.30, No.6 November, pp. 961-978.

The World Bank/International Bank for Reconstruction and Development (2006). Global Economic Prospects, Economic Implications of Remittances and Migration 2006, 34320, Washington, DC

Wimmer, Andreas \& Nina Glick Schiller (2002). Methodological nationalism and beyond: nation-state building, migration and the social sciences. Global Networks, Volume 2, Issue 4, pp. 301-334.

Yuval-Davis, Nira (2007): Nationalism, Belonging, Globalisation and Ethics of Care in Kvinder, Kon EForskning 2-3, 91-100.

* This article is based on a paper presented at the 19th Annual Meeting on Socio-Economics, CBS, International Centre for Business and Politics, Copenhagen, Denmark, June 30, 2007, Changing Political Economies: Macro Trends and Micro Experiment Research Network: Race, Ethnicity and Immigration

${ }^{1}$ Also referred as destination country, receiving country, country of settlement, host country, while country of origin is referred as the source country, sending country or ancestral country.

2 Many people in Pakistan are depended on remittance. The World Bank estimated that the remittance to Pakistan in 2001 and 2006 constitute respectively 1,9\% and 2\% of the country's GNP, whereas IMF in 2002 estimated the remittance to be $6 \%$ of the country's GNP (Carling 2005, The World Bank 2006). Pakistan is number $12^{\text {th }}$ on the list of countries receiving most remittance in the world (The World Bank 2006), and these figures are based on remittances that are transferred through official channels.

${ }^{3}$ The use of transnationalism as a concept for studying the contributions of second generation Pakistani in Denmark to development in Pakistan should be considered with caution in the present study because there is limited understanding of the ways in which various factors such as level of education, class, gender, caste, or regional origin affect their involvement (Al-Ali, Black and Koser 2001).

${ }^{4}$ They have established a business firm in the field of pharmacy as her husband had masters in Pharmacy and Biotechnology. 
${ }^{5}$ Zakat is one of Islam's five columns - a kind of tax that is paid by believing Muslims.

\section{Authors}

Rashmi Singla is an associate professor in the Department of Psychology and Educational Studies at Roskilde University, Denmark and also affiliated to NGO Transcultural Therapeutic Team for Ethnic Minority Youth and their Families (TTT) in Copenhagen. Anne Sophie Fabricius and Anne Holm are both Cand. scient. soc. from Roskilde University, Denmark. Email for corresponding author (Singla): rashmi@ruc.dk 